\title{
Assessing the Influence of the MJO on Strong Precipitation Events in Subtropical, Semi-Arid North-Central Chile $\left(30^{\circ} \mathrm{S}\right)$
}

\author{
CRISTÓBAL JULIÁ \\ Centro de Estudios Avanzados en Zonas Áridas, La Serena, Chile \\ DAVID A. RAHN \\ Departamento de Geofísica, Facultad de Ciencias Físicas y Matemáticas, Universidad de Chile, Santiago, Chile \\ José A. RutLlant \\ Departamento de Geofísica, Facultad de Ciencias Físicas y Matemáticas, Universidad de Chile, Santiago, and Centro \\ de Estudios Avanzados en Zonas Áridas, La Serena, Chile
}

(Manuscript received 23 November 2011, in final form 21 March 2012)

\begin{abstract}
Annual precipitation in subtropical, semiarid north-central Chile $\left(30^{\circ} \mathrm{S}\right)$ during rainy years comprises a few (3-5) strong events in the fall and winter, which are presumably modulated by the Madden-Julian oscillation (MJO). Precipitation from 1979-2009 was recorded daily at three stations along the Elqui Valley. The relationship between the MJO and precipitation is investigated from two perspectives: 1) examining a MJO index (MJOI) based on the actual precipitation events and 2) examining the likelihood of precipitation based on a favorable MJOI. About $80 \%$ of the strong precipitation events at the coast in La Serena are related to an active MJO near the central equatorial Pacific. These events are often typified by broad, slow moving synoptic systems in phase with the MJO propagation. Blocking in the far southeast Pacific is associated with precipitation $75 \%$ of the time, while deep troughs make up the rest.

A relationship between a MJOI and strong rainfall suggests that, though it could be used as a potential diagnostic, the number of cases where there is a favorable MJOI but no precipitation (i.e., false alarms) limits its utility. Additional criteria such as the Southern Oscillation (SO) and Antarctic Oscillation (AAO) phases were used to reject false alarms. Rejecting cases with positive values of the SO index reduced the number of false alarms from $70 \%$ to $58 \%$, leaving about two false alarms for every correctly diagnosed event. The AAO index could not discriminate between false alarms and real cases. While a favorable MJOI increases the likelihood of precipitation in the Elqui Valley, false alarms remain problematic.
\end{abstract}

\section{Introduction}

Average annual precipitation along the Elqui Valley in north-central Chile $\left(30^{\circ} \mathrm{S}\right)$ ranges from about $80 \mathrm{~mm}$ at $\mathrm{La}$ Serena (near sea level) to near $180 \mathrm{~mm}$ at La Laguna Dam, located at $3150 \mathrm{~m}$ altitude in the southeast branch of the upper Elqui Valley (Fig. 1). Like other subtropical semiarid climates, precipitation is concentrated in fall and winter (April-September) with large interannual variability (Fig. 2). Large annual precipitation tends to coincide

Corresponding author address: David A. Rahn, Departamento de Geofísica, Universidad de Chile, Blanco Encalada 2002, Santiago, Chile.

E-mail: darahn@gmail.com with the development of a warm event of the El NiñoSouthern Oscillation (ENSO) cycle (El Niño), whereas droughts are common during the opposite phase of this cycle (La Niña). Precipitation totals during rainy years primarily consist of a few (three to five) strong rainfall episodes, possibly connected to an intraseasonal modulation of the rainfall-favorable conditions associated with El Niño, which include a weaker subtropical anticyclone and equatorward-shifted storm tracks in connection with more frequent blocking of the westerlies in the high latitudes of the southeast Pacific (Rutllant and Fuenzalida 1991).

When analyzing dry spells during wet winters in central Chile, Rutllant and Fuenzalida claim that those alternating rainfall anomaly patterns are compatible with intraseasonal oscillations. Furthermore, Rutllant and Aceituno 


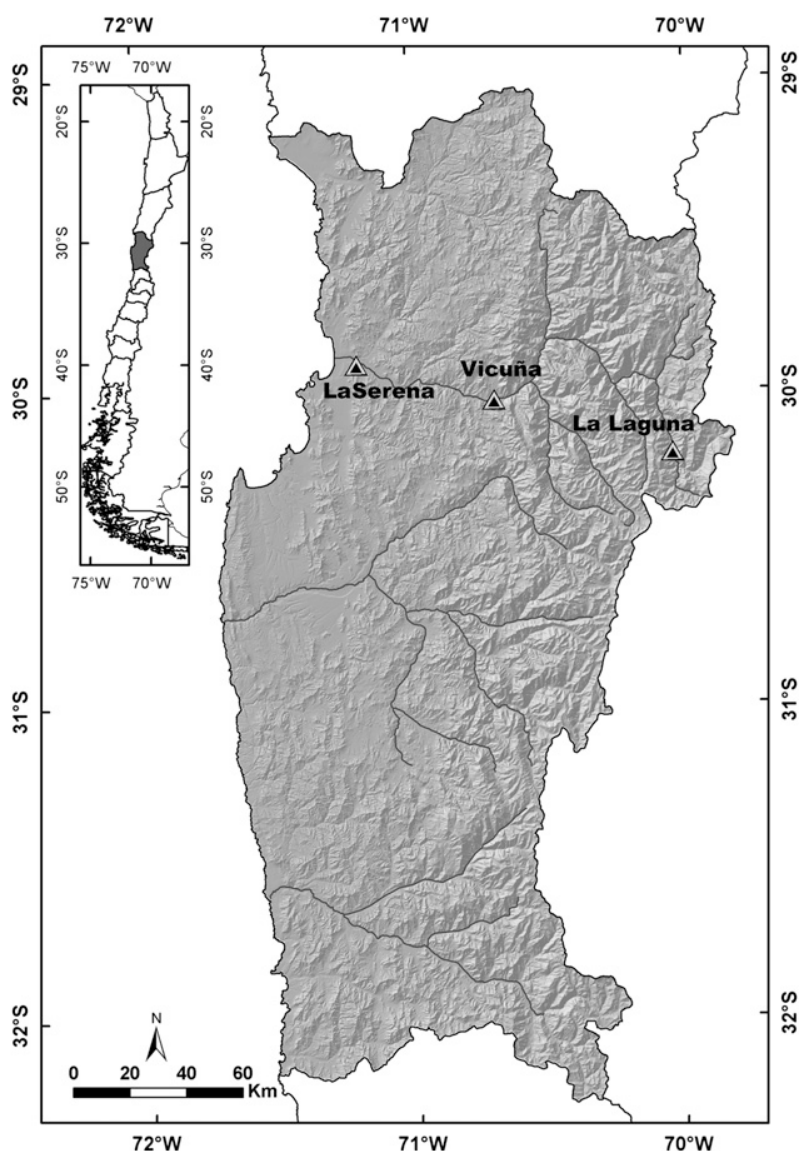

FIG. 1. Meteorological stations along the Elqui Valley in semiarid north-central Chile $\left(30^{\circ} \mathrm{S}\right)$.

(1991) found a direct connection between westerly wind anomalies in the central equatorial Pacific (immediately westward of convective clusters) and positive geopotential height departures at 500 and $200 \mathrm{hPa}$ in the high latitudes of the southeast Pacific. These results are consistent with intraseasonal modes of the Pacific-South America (PSA) teleconnection pattern between the central equatorial Pacific convective clusters and downstream at higher latitudes through the South Pacific to South America (Mo and Higgins 1998a). Hormazabal et al. (2002) analyzed satellite-derived surface winds over the southeast Pacific and found positive correlations between westerly wind anomalies in the central tropical Pacific and northerly wind anomalies at $30^{\circ} \mathrm{S}$ off the Chilean coast, the latter representing a weakening of the southeast Pacific subtropical anticyclone.

More recently, in a global-scale analysis of precipitation anomalies Donald et al. (2006) found a significant association of positive rainfall anomalies in central Chile with an active Madden-Julian oscillation (MJO) (Madden and Julian 1994). Convection over the central equatorial Pacific in austral winter is associated with

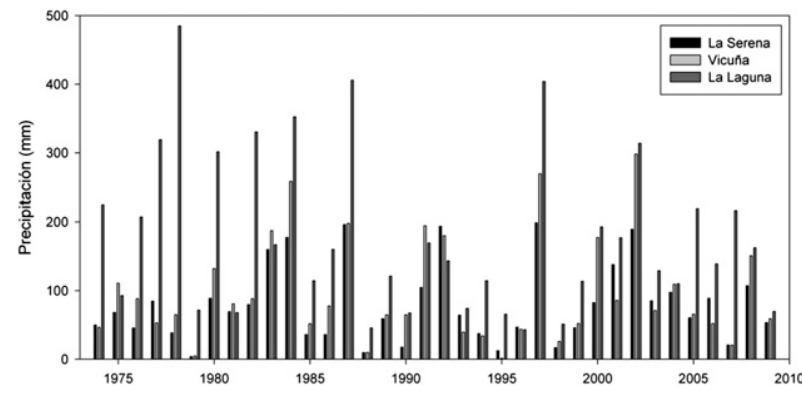

FIG. 2. Annual precipitation $(\mathrm{mm})$ at three sites along the Elqui Valley: La Serena (black), Vicuña (light gray), and La Laguna (dark gray).

negative (positive) anomalies in the standardized mean sea level pressure in the subtropical (subpolar) southeast Pacific. Carrasco (2006) also explored the relation between the MJO and precipitation at eight stations throughout central Chile $\left(30^{\circ}-38^{\circ} \mathrm{S}\right)$ and found a significant correlation at all but two stations and recognized its potential use for long-term forecasting. Barrett et al. (2012) used satellite and rain gauge data to document the effects of the MJO on precipitation for all of Chile and the associated anomalies in the atmospheric circulation, stressing the importance of the teleconnection from the convective activity over the equatorial Pacific.

This work assesses the relationship of the MJO with moderate to strong precipitation events as recorded at $\mathrm{La}$ Serena, Vicuña, and La Laguna Dam at 150, 650, and $3150 \mathrm{~m}$ MSL, respectively. These stations, located along the semiarid Elqui Valley in north-central Chile $\left(30^{\circ} \mathrm{S}\right)$, have collected data over the last 31 years (1979-2009). In section 2 the data sources and analysis methods are described. Section 3 contains the results from two perspectives: 1) examining the meteorological features and links to a MJO index (MJOI) based on the actual precipitation events (storm perspective) and 2) examining the meteorological features and likelihood of precipitation based on a precipitation-favorable MJOI (MJO perspective). The analysis focuses on La Serena, but data from the other stations is also shown and has similar features since precipitation often occurs simultaneously at all stations. We explore an application of 2) by examining the possibility of using the MJOI to assess the predictability of such precipitation events given a perfect forecast of the MJOI or information on the precursor phases of the MJOI. A synthesis and discussion of the results are provided in section 4 .

\section{Data and methods}

Time series of daily precipitation for La Serena, Vicuña, and La Laguna Dam were obtained from the Dirección 
TABLE 1. Summary of the conditions for the strong events at each of the observing stations in the Elqui Valley from the storm perspective.

\begin{tabular}{|c|c|c|c|c|c|c|c|}
\hline & Strong events & MJO any phase & $\begin{array}{c}\text { MJO } \\
\text { phase } 7,8,1,2\end{array}$ & $\begin{array}{l}\text { Previous } \\
\text { phases 3-4 } \\
\text { and 5-6 }\end{array}$ & $\begin{array}{l}\text { Previous } \\
\text { phase only } \\
5-6\end{array}$ & Blocking & Deep trough \\
\hline La Serena & 33 & 27 & 25 & 17 & 6 & 25 & 8 \\
\hline Vicuña & 35 & 27 & 20 & 16 & 4 & 25 & 10 \\
\hline La Laguna & 21 & 16 & 14 & 11 & 2 & 13 & 6 \\
\hline
\end{tabular}

General de Aguas (DGA, Chile) for the 31-yr period from 1979 to 2009. Meteorological data were obtained from the National Centers for Environmental Prediction's Climate Forecast System Reanalysis (CFSR) (Saha et al. 2010). This reanalysis is available at a maximum resolution of $0.3^{\circ}$ every $6 \mathrm{~h}$ from 1979 until the present. The phase (1-8) and amplitude (intensity) of the MJO come from a MJOI defined by Wheeler and Hendon (2004; http://www.cawcr. gov.au/staff/mwheeler/maproom/RMM/) through principal components of the multivariate empirical orthogonal functions. Since most of the precipitation is centered in austral winter, only the April-September period is considered. Here we define an "active" MJO as any time when the amplitude of the MJOI is significant. Because the MJO tends to be more coherent and stronger in austral summer-fall, significant amplitudes of the MJOI are defined as those $\geq 1.0$ during fall (April-June) and $\geq 0.7$ during winter (July-September) to simply include more cases. Other definitions of an active MJO require a minimum duration and regular eastward propagation (e.g., L'Heureux and Higgins 2008), but we opted for a simpler definition. There will, however, be a discussion on the regularity of the MJOI propagation for the cases of strong precipitation in La Serena.

Two general atmospheric circulation indices are also considered: the Southern Oscillation index (SOI) (http:// www.cpc.ncep.noaa.gov/data/indices/soi), which may be considered as a proxy for anomalies in the strength of the southeast trade winds (positive for La Niña and negative for El Niño) and, hence, the strength of the southeast Pacific subtropical anticyclone, and the Antarctic Oscillation index (AAOI) (http://jisao.washington.edu/data/ $\mathrm{aao} /$ ), which represents anomalies in the latitudinal position of the westerly wind belt and associated storm tracks. Given that just three to five strong precipitation events characterize rainy years in this region, strong (moderate) rainfall events have been defined as those for which the total precipitation of the event equals or exceeds $25 \%(12 \%)$ of the average annual accumulation at the corresponding station over one or more consecutive days. Therefore, thresholds for strong (moderate) events have been set to 20, 25, and $40 \mathrm{~mm}(10,15$, and $25 \mathrm{~mm})$ for $\mathrm{La}$ Serena, Vicuña, and La Laguna, respectively.

\section{Results}

\section{a. Storm perspective}

At La Serena there are 65 cases that occurred from 1979 to 2009 during austral fall and winter that have at least moderate rainfall $(\geq 10 \mathrm{~mm})$ - of which 33 are classified as strong rainfall events $(\geq 20 \mathrm{~mm})$. Primary emphasis of the results is placed on strong events since these are more prone to disaster scenarios including flooding and landslides. Highlights of the following discussion are summarized in Table 1, which also include Vicuña and La Laguna that have similar results to $\mathrm{La}$ Serena. The strong rainfall episodes at La Serena are associated with persistent rainfall since $91 \%$ of the cases last 2 or more days with a median of 2 and an average of 2.6 days. This suggests a tendency toward slow-moving systems rather than being intense and short lived. More than half (17 of 33) of the strong rainfall events at La Serena happened simultaneously with precipitation at the other two stations, indicating that the strong events tend to be nonlocal phenomena and are often energetic enough to penetrate all the way up the valley. All of these events occurred while there was an active MJO next to the central equatorial Pacific. Although simultaneous precipitation at all three locations in the Elqui Valley increases the chances of flooding downstream, snow accumulation in the upper watershed secures water supply during the growing and dry seasons.

Significant amplitudes of the MJOI are associated with $78 \%$ (51 of 65 ) of the moderate to strong events, increasing to $82 \%$ ( 27 of 33 ) in the case of the strong events at La Serena. A frequency distribution of these 27 with respect to the MJOI phase illustrates the dependence on the location of the equatorial convective complex (Fig. 3). While the frequency of moderate and strong events peaks at phase 1 and reaches a minimum at phases 4 and 5, 25 out of 27 strong events are concentrated in phases 7, 8, 1, and 2 when the convective phases of the MJO drift eastward over the central equatorial Pacific (i.e., from $140^{\circ} \mathrm{E}$ to $140^{\circ} \mathrm{W}$, around the date line). No strong precipitation episodes have happened during phases 4-6 over the last 30 years. It is interesting to note that during a strong El Niño the convection associated with phase 2 is more 


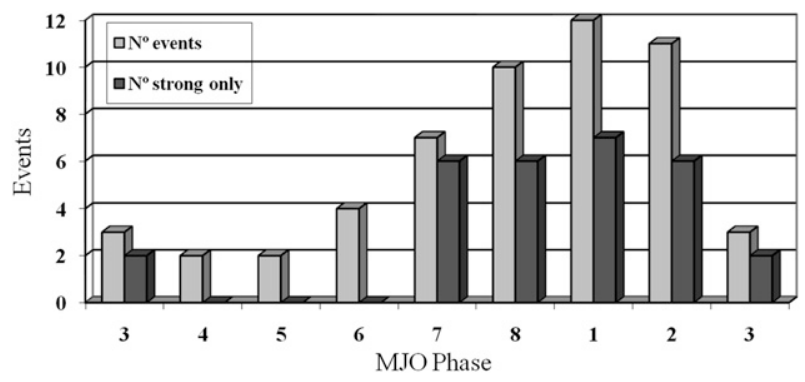

FIG. 3. Distribution of the number of moderate and strong (light gray) and strong only (dark gray) rainfall events for each phase bin of the MJOI (Wheeler and Hendon 2004).

intense and reaches farther eastward, rather than being damped short of crossing the central equatorial Pacific (e.g., Hendon et al. 1999; Kessler 2001).

Since the MJO is an irregular oscillator, the eastward advancement of the equatorial convection is examined to understand its propagation previous to the precipitation events in La Serena. Figure 4 depicts the state of the MJOI during the 15 days prior to the rain event, from light gray at day -15 toward darker colors and the rain event is indicated by a black square. While many of the individual events are preceded by an eastward (counterclockwise) propagation of the equatorial convection in a "regular" way, there are events with erratic behavior. It is not always the case that there is a significant MJO in the previous phases, but it is common. For instance, 17 of the 25 strong events under a favorable $\mathrm{MJO}$ also had an active MJO in both the previous phases 3-4 and 5-6, while an additional 6 cases were preceded by a significant phase of just 5-6 (not in 3-4). A simple average of the 15-day progression starts in the middle of phase 6 and ends between phases 1 and 8 . Regardless of the occasional irregular propagation of the $\mathrm{MJO}$, there is a link between abnormally strong convection located in phases $7,8,1$, or 2 and favorable precipitation conditions in central Chile, consistent with the PSA teleconnection pattern at interseasonal time scales (e.g., Mo and Higgins 1998a).

A similar circulation anomaly pattern stands for the interannual time scale when favorable conditions for precipitation in north-central Chile are present during the developing stage of El Niño (in austral winter-spring when convection has drifted to the vicinity of the central equatorial Pacific). Favorable conditions include a weaker subtropical anticyclone and storm tracks shifted equatorward that coincide with more frequent blocking of the westerlies (i.e., persistent positive geopotential height anomalies throughout the troposphere) in the high latitudes of the southeast Pacific (Rutllant and Fuenzalida 1991). Therefore, anomalous circulation features favorable to the development of precipitation in central Chile during the warm ENSO phase seem to be modulated

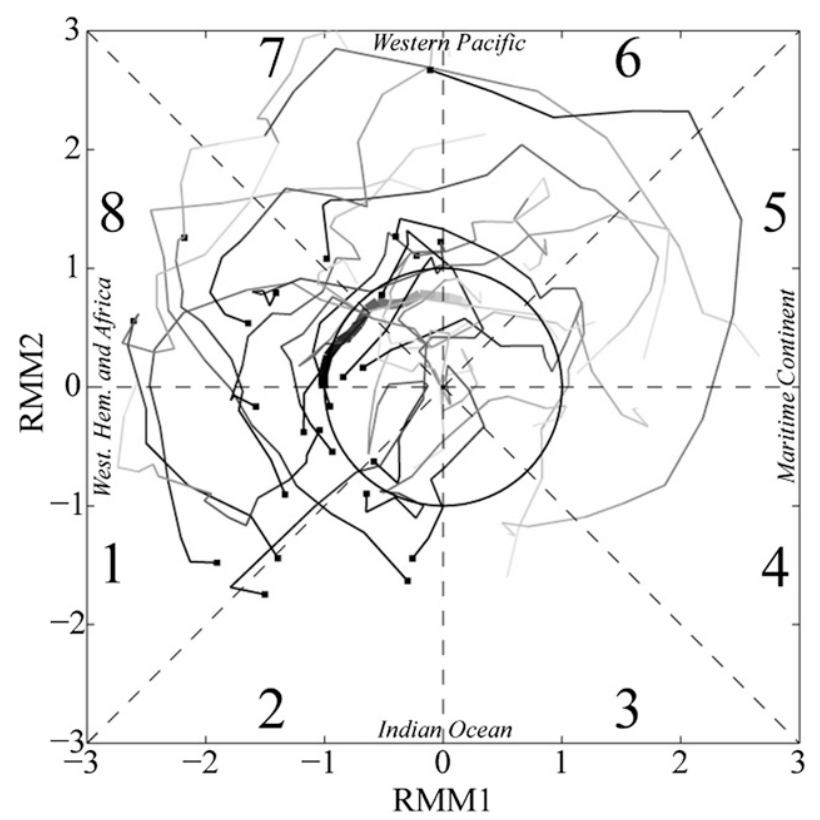

FIG. 4. A phase space diagram depicting the state of the MJO for the rain events associated with an active MJO in La Serena. The actual event is indicated by the small solid square and its tail extends from the rain event (black) back until 15 days (light gray). The thick line is the average of all oscillations.

by the MJO, producing alternating enhancement and weakening of such features. An example of such a blocking pattern at $500 \mathrm{hPa}$ is shown in Fig. 5a and consists of a negative height (cyclonic) anomaly north of a positive height (anticyclonic) anomaly. The other common feature depicted in Fig. $5 b$ is a deep trough pattern associated with an elongated negative height (cyclonic) anomaly with a northwest-southeast axis immediately west of South America and the Antarctic Peninsula. For 25 of the 33 (75\%) strong precipitation events at La Serena, a blocking pattern was present, and the other 8 events $(25 \%)$ were characterized by a deep trough. This indicates that the blocking pattern, while the most common, is not a necessary feature.

A composite of synoptic conditions associated with the strong precipitation events that occur during an active MJO is illustrated in Fig. 6. The exact synoptic features do vary from event to event but share the common features that appear in the composite. The surface cyclone is present two days before the rain event and it intensifies while its center moves northward beneath a $500-\mathrm{hPa}$ trough that extends equatorward (sometimes developing into a cutoff low as seen in the individual cases). Low-level westerly wind intensifies as the trough approaches the north-central Chilean coast and diminishes as the upperlevel features slowly progress eastward. The broad, slow moving features are consistent with being "teleconnected" 

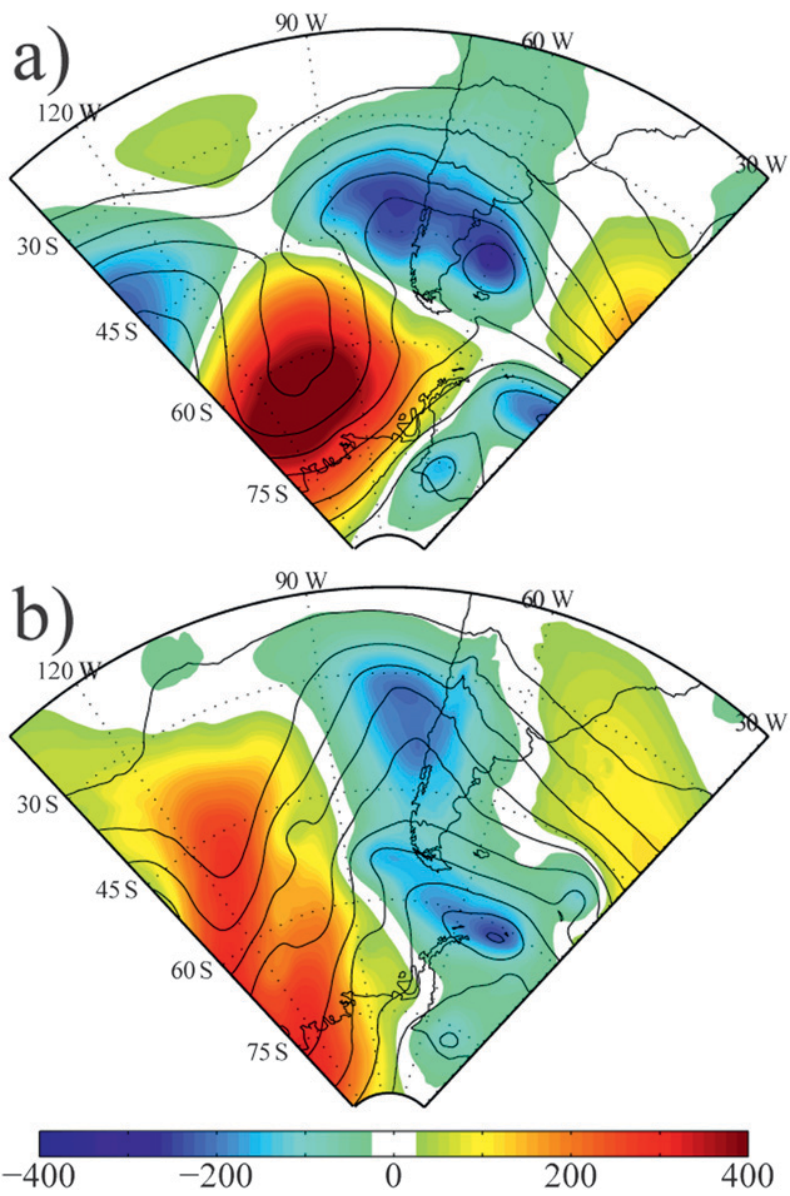

FIG. 5. The 500-hPa geopotential height (m, contours) and their anomaly from the 30-yr CFSR climatology (color, m) for (a) an example of a blocking scheme on 10 Apr 1980 and (b) an example of a deep-trough scheme on 4 Jun 2002.

to the convective complex in the equatorial regions, impacting a broad area and moving eastward at near the same speed as the convective complex, which takes several days to progress from phase to phase. The result is persistent rain over the Elqui Valley with a stronger than normal westerly wind component that would contribute to enhanced orographic precipitation up the valley.

Examining the six cases of strong precipitation that were not associated with an active MJO, we find several different situations. One case was a 2-day event in La Serena and Vicuña with an MJOI in phase 2 but with amplitude slightly below the defined threshold (0.6 instead of 0.7) during El Niño conditions that could be considered a marginal case. Three other events were also observed during the warm phase of the SO (negative SOI). In particular, two of them presented a negative SOI and a negative AAOI, both contributing to rainfall favorable conditions: a weaker subtropical anticyclone and an equatorward shift in the westerlies. The last two events occurred during nearneutral conditions and correspond to cutoff lows, which are largely independent of the ENSO phase (Fuenzalida et al. 2005).

Changes in the subtropical anticyclone and shifts in the westerlies are succinctly represented by the aforementioned general circulation indices. Anomalies related to changes in those indices are useful in diagnosing their relative contribution to strong precipitation in northcentral Chile. Most important are the changes to the surface pressure field (weakening of the anticyclone) and zonal wind (strengthening of the westerlies that enhance orographic precipitation). To this end, composites based on each index were created for 31 years of CFSR data utilizing only data from May to August (Fig. 7). Only significant anomalies in the zonal wind are shown. Significance is determined by Monte Carlo experiments at the $90 \%$ level. For each point a random subset of 20 days is resampled and averaged and this is repeated 1000 times to construct a distribution. The null hypothesis that the mean of the distribution is zero is rejected if zero lies in the lower $5 \%$ or upper $95 \%$ of the distribution. When the null hypothesis is rejected, the mean is significant. On the left are the unfavorable conditions for precipitation: positive AAO, positive SOI (i.e., La Niña), and MJOI in phase 4,5 , or 6 . On the right are the favorable conditions for precipitation: negative AAO, negative SOI (i.e., El Niño), and MJO in phase 7, 8, 1, or 2. When the conditions are favorable, the anticyclone is weakened by $0.75-2.25 \mathrm{hPa}$ and westerly wind off the Chilean coast is increased by $0.5-1 \mathrm{~m} \mathrm{~s}^{-1}$. The exact position of the anomalies varies between the indices, but maximum pressure anomalies are centered on $40^{\circ} \mathrm{S}$ and zonal wind anomalies are centered on $30^{\circ} \mathrm{S}$.

There is likely interaction between the favorable conditions of each index. Interdependence of the indices has been proposed by Carvalho et al. (2005) who found that $25 \%$ of the AAO variance was linearly related to the state of ENSO. Given the similar time scales of the AAO and MJO (30-60 days), Matthews and Meredith (2004) suggested that seven days after convection in the equatorial Indian Ocean the AAO reaches a maximum. Conversely, Pohl et al. (2010) argued that at intraseasonal time scales both the AAO and ENSO and also the AAO and MJO have insignificant correlations. However, Pohl and Matthews (2007) showed that El Niño (La Niña) conditions are associated with faster (slower) eastward propagation of the MJO convective complex and shorter (longer) lifetimes during the equinoctial seasons (MarchMay and October-December). Therefore, if the indices are largely independent of each other, one would expect to see constructive or deconstructive behavior in their 

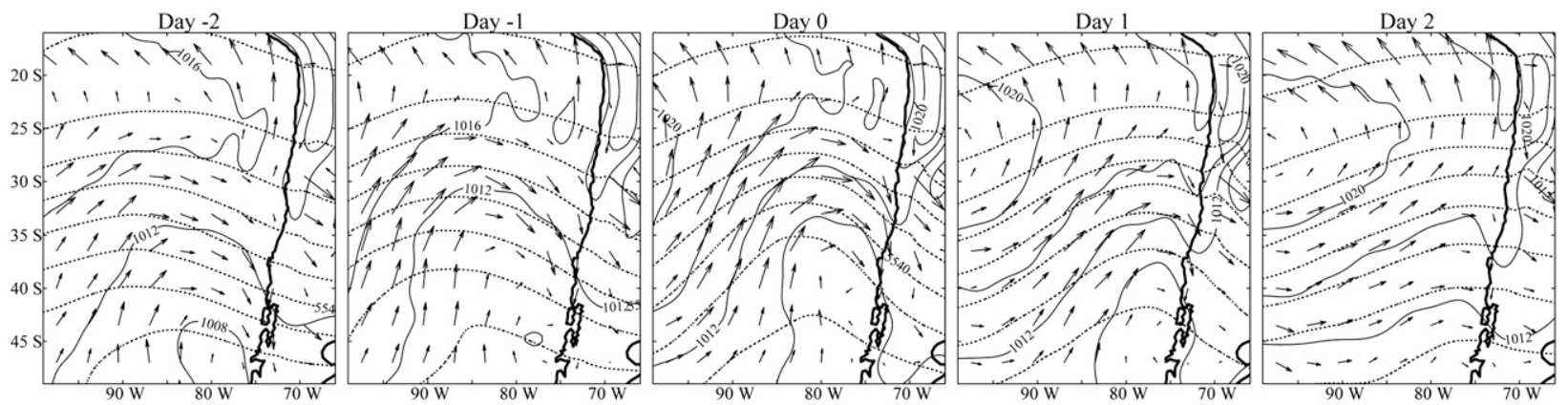

FIG. 6. Composite of the mean sea level pressure (hPa, solid), 10-m wind ( $\mathrm{m} \mathrm{s}^{-1}$, vectors), and 500-hPa height (gpm, dotted contours) for the strong precipitation events associated with a favorable MJOI.

signals. For example, an MJOI in phase 7, 8, 1, or 2 during El Niño may result in a larger anomaly than either alone. Regardless of the fundamental interrelations, it is practical to know how these potentially interact. Favorable (unfavorable) conditions during the rainy season are combined together and their composites are shown on the right (left) of Fig. 8. As implied by the frequent occurrence of both El Niño and an MJO in phase 7, 8, 1, or 2 during precipitation events, these do indeed show a constructive behavior. The favorable combinations show negative pressure anomalies between 2.5 and $3.5 \mathrm{hPa}$ and westerly wind anomalies increasing to $1-1.5 \mathrm{~m} \mathrm{~s}^{-1}$ over a broad area. Between all of the combinations of indices, the composites of the synoptic conditions during heavy rain events best resemble the combined El Niño and MJO in phases $7,8,1$, and 2 .

Not shown are the composites that are deconstructive, that is, combining a favorable and unfavorable index. Not surprisingly, combining favorable with unfavorable indices leads to only small anomalies, so the figure is essentially void of significance. Nevertheless, the impact of this finding is important because it demonstrates that, even if there is a favorable and strong MJO (phase 7, 8, 1 , or 2) but it takes place during La Niña, for example, the competing anomalies would tend to cancel any favorable signal normally produced by the MJO alone and decrease the likelihood of a strong precipitation event.

\section{b. MJO perspective}

In the previous section the synoptic conditions and state of the MJOI were identified based on the observed precipitation events. It was found that, when precipitation occurred, the MJOI was predominately in phase $7,8,1$, or 2. In this section the problem is approached from the other direction: the likelihood of precipitation is explored based on the MJOI. Both approaches provide a diagnostic relationship between the $\mathrm{MJO}$ and the precipitation in the Elqui Valley. Furthermore, by using the MJOI as an indicator for the likelihood of precipitation it may be possible to use the developed diagnostic relationship and a predicted MJOI as a forecasting tool.

Each MJOI precipitation-favorable period is examined to identify if a rain event occurred or not. Given that precipitation in this semiarid climate is in general scarce, it is likely to have a MJOI favorable for an event but no precipitation occurs (i.e., "false alarms"). In fact, utility of the MJOI to identify rain events would be severely limited if there were too many false alarms. To assess such occurrences, periods that fulfill the condition of the MJOI amplitude above the threshold and in phase $7,8,1$, or 2 were selected and are classified into a hit (favorable MJOI and an event occurred), a miss (unfavorable MJOI but an event occurred), or a false alarm (favorable MJOI but no event occurred). From this information, the probability of detection (POD) and false alarm rate (FAR) are calculated. For each station, the data is broken down into moderate only, strong only, and either moderate or strong events. The results between the stations are similar and are summarized in Table 2. Strong cases have the highest POD rate of $\sim 0.75$ for strong events, but the FAR is 0.84 0.90 . The FAR is decreased for cases of either moderate or strong precipitation, but the POD decreases as well since the moderate cases are harder to detect using the MJOI and have a POD of $0.43-0.52$ for the three stations.

Due to the abundance of false alarms, we may conclude that the MJOI alone is not sufficient to unambiguously identify the precipitation events. Using just the cases with an active MJO (excluding misses), during austral autumn (winter), about $25 \%$ (35\%) events that are moderate or strong are correctly diagnosed using just the MJOI, leaving about $75 \%(65 \%)$ as false alarms. To reduce the number of false alarms, other criteria are sought to discard unlikely days and are summarized in Table 3. Consistent with the constructive (deconstructive) interference of concurrent favorable (unfavorable) conditions in the $\mathrm{SO}$ and AAO demonstrated by the composites in Fig. 8, the number of false alarms may be decreased using this additional information. Discarding events when the 

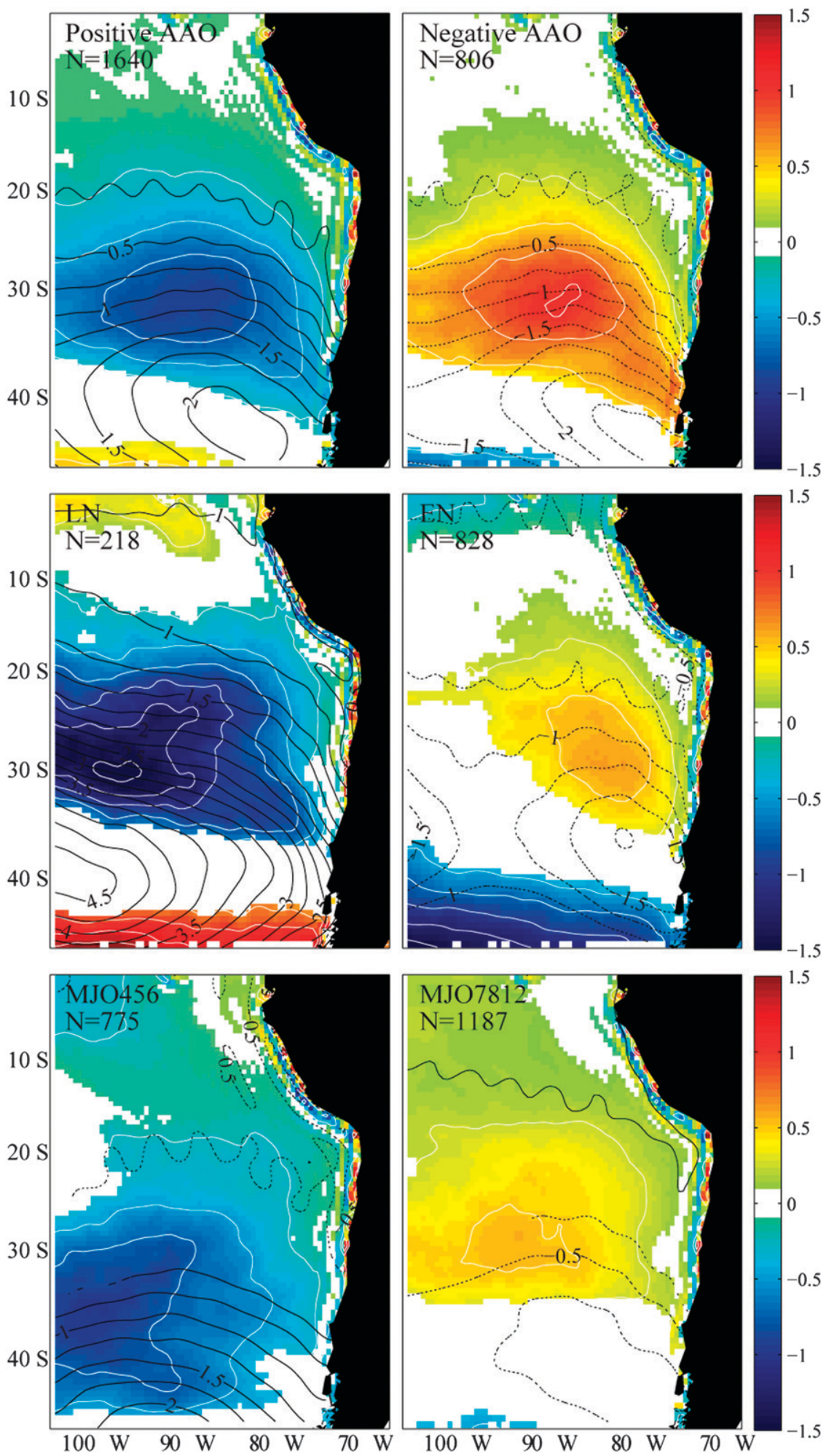

FIG. 7. Composites from the CFSR from May to August based on climate indices of the anomalies in surface pressure ( $\mathrm{hPa}$, contours with negative dashed and positive solid) and 10-m zonal wind ( $\mathrm{m} \mathrm{s}^{-1}$, color). The climate index (EN: negative SOI, LN: positive SOI; MJOnnn indicates the MJOI phases) and number of days (N) is indicated in the upper left of each panel. Only significant zonal wind anomalies are plotted. 

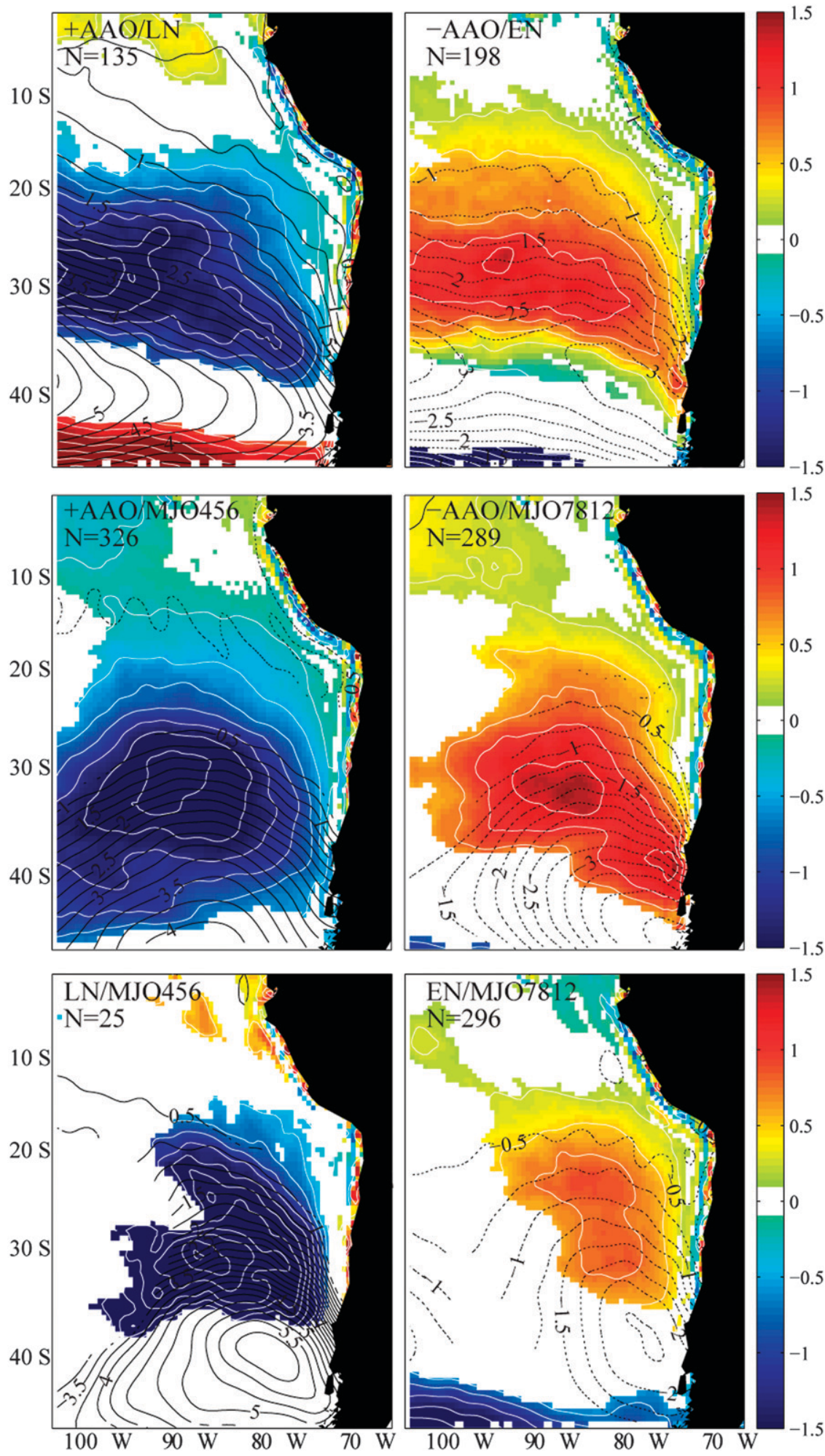

FIG. 8. As in Fig. 7 but for combinations of indices that are indicated in the upper left of each panel. 
TABLE 2. Summary of the MJOI-precipitation diagnostic from the MJO perspective.

\begin{tabular}{lcccccc}
\hline \hline & Events & Hits & Misses & False alarms & POD & FAR \\
\hline \multicolumn{7}{c}{ La Serena } \\
Moderate & 32 & 15 & 17 & 141 & 0.47 & 0.90 \\
Strong & 33 & 25 & 8 & 140 & 0.76 & 0.85 \\
Both & 65 & 40 & 25 & 108 & 0.62 & 0.73 \\
& \multicolumn{7}{c}{ Vicuña } & & & \\
Moderate & 29 & 15 & 14 & 144 & 0.52 & 0.91 \\
Strong & 35 & 26 & 9 & 138 & 0.74 & 0.84 \\
Both & 64 & 41 & 23 & 109 & 0.64 & 0.73 \\
& & & & & & \\
& & & La Laguna & & & \\
Moderate & 30 & 13 & 17 & 143 & 0.43 & 0.92 \\
Strong & 21 & 16 & 5 & 152 & 0.76 & 0.90 \\
Both & 51 & 29 & 22 & 122 & 0.57 & 0.81 \\
\hline
\end{tabular}

SOI $\geq 0.6$ (i.e., La Niña) reduces the number of false alarms to $63 \%$ (53\%) in fall (winter). A threshold of 0.6 is used because it optimally rejects false alarms without rejecting correctly diagnosed events. Using this criterion, one event with $11.5 \mathrm{~mm}$ of precipitation only at La Serena during autumn and one event during winter with $23.3 \mathrm{~mm}$ only at Vicuña during winter would also be discarded but, since these events are marginal, the error is acceptable. Using the SOI decreases the number of false alarms by eliminating events during La Niña conditions when precipitation is unlikely even given a favorable MJOI.

Using the AAOI as an additional criterion further reduces the amount of false alarms, but at the cost of incorrectly discarding several real events of strong precipitation. If the SOI $\geq 0.6$ or the AAOI $\geq 0.6$, the number of false alarms is reduced to $46 \%(32 \%)$ in fall (winter), but $8 \%(9 \%)$ of the total cases are incorrectly discarded. This is a large number since $31 \%(26 \%)$ of the precipitation events are not retained in the fall (winter). While SOI is a good criterion to detect and discard false alarms, the AAO is not because it is unable to efficiently discriminate between events with and without precipitation. As a result, AAO should not be used as an additional criterion for eliminating false alarms.

So far, only a diagnostic relating the MJOI to precipitation has been discussed. Ideally, the relationship of that diagnosis would be used to help guide forecasters toward predicting the likelihood of precipitation over the Elqui Valley. This requires either a prediction of the MJOI through numerical methods or considering the precursor phases. Although there is skillful predictability of the MJOI through numerical methods, the exact limit of how many days in advance is still an unresolved issue. Since the MJO is a slow oscillator, it is reasonable to think that the long-range predictability would be from four weeks to two months (e.g., Van den Dool and Saha 1990). The actual skillful prediction of the MJO from numerical and statistical models is currently closer to 15-20 days (e.g., Goswami and Xavier 2003; Fu et al. 2007; Jiang et al. 2008; Seo et al. 2009) with a theoretical upper limit of $\sim 30$ days that was put forth by Waliser et al. (2003). So, we can likely obtain skillful forecasts of the future state of the MJOI with a lead time of at least two weeks making the MJOI a viable long-term forecast tool. Considering the precursor phase is another viable method since often there is regular propagation of a strong MJO. In fact, from Table 1 , for 23 of the 25 strong precipitation events associated with a favorable MJOI there was also a significant amplitude in the previous phases of 3-4 and 5-6 or just 5-6.

False alarms remain to be a problem in such a semiarid climate, and it is unlikely that it will be entirely alleviated by other criteria. Assuming a perfect forecast of the MJOI that can be used to flag possible events and discarding events with SOI values $\geq 0.6$, between half and a third of the possible events turn out to be falsely predicted. Given this, a forecaster could still use these criteria as an early warning indicator of possible strong precipitation events, keeping in mind the high tendency for false alarms. This, in addition to the misses (cases that are not associated with an active MJO), limit longterm predictability. We can conclude here that there is an increased likelihood for precipitation during the favorable MJO period, but one must be aware of the number of false alarms.

\section{Conclusions and discussion}

Precipitation in the semiarid Elqui Valley is an important issue due to its infrequent nature with only a few

TABLE 3. Summary of the percentage of events at La Serena during a favorable MJOI including discarding events based on SOI and AAOI.

\begin{tabular}{|c|c|c|c|c|c|c|}
\hline \multirow[b]{2}{*}{ Event } & \multicolumn{2}{|c|}{ No discarding } & \multicolumn{2}{|c|}{$\mathrm{SOI} \geq 0.6$} & \multicolumn{2}{|c|}{$\mathrm{SOI} \geq 0.6$ or $\mathrm{AAOI} \geq 0.6$} \\
\hline & Fall & Winter & Fall & Winter & Fall & Winter \\
\hline False alarms & 75 & 65 & 63 & 53 & 46 & 32 \\
\hline Correctly predicted and not discarded & 25 & 35 & 24 & 34 & 17 & 27 \\
\hline Discarded correctly & 0 & 0 & 12 & 12 & 29 & 32 \\
\hline Real event discarded & 0 & 0 & 1 & 1 & 8 & 9 \\
\hline
\end{tabular}


strong precipitation events making up much of the total annual rainfall in rainy years, largely associated with El Niño and neutral phases of the ENSO cycle. Surface stations along the Elqui Valley at three locations were used to identify precipitation events over the last 31 years (1979-2009). Specifically, an active MJOI in phase 7, 8, 1, or 2 is associated with intense precipitation events often characterized by a broad, slow-moving cyclone consistent with a large-scale teleconnection pattern. No strong events have happened during an MJOI in phase 4, 5, or 6 . Blocking of the westerlies in the high latitudes of the southeast Pacific is associated with $75 \%$ of the events, while a deep trough in the midtroposphere off the Chilean coast characterizes the rest. Blocking can be linked to a positive PSA teleconnection pattern, while the deep trough is consistent with a negative PSA teleconnection pattern (Mo and Higgins 1998a; Vargas et al. 2006). Composites of the anomalous surface pressure and zonal surface wind during favorable (unfavorable) conditions in the MJO, ENSO, and AAO revealed their individual influence on the region and combining the composites revealed their constructive (destructive) interference. The composite that included both the MJO in phases 7, 8 , 1, and 2, and also El Niño had similar conditions to the composite of the synoptic conditions during strong precipitation events.

Knowing that for many of the precipitation events the MJOI is in phase $7,8,1$, or 2, the periods with a favorable MJOI were examined to determine hits, misses, and false alarms. Approaching the problem in that way allowed an assessment of the MJOI as a diagnostic for precipitation events. While POD was 0.75 for strong precipitation, the FAR was 0.85 . Of all the times when there is a favorable MJOI, for the fall (winter) there are $25 \%(35 \%)$ correctly diagnosed precipitation events while the remaining $75 \%(65 \%)$ are false alarms. Discarding events during La Niña (SOI $\geq 0.6$ ) reduced the amount of false alarms by $12 \%$. The same was attempted with the AAO but, despite the apparently favorable and unfavorable conditions associated with the AAO, it was unable to effectively differentiate between precipitation and nonprecipitation events. This is consistent with Montecinos et al. (2011) who found that the relationship between the first principle component of precipitation in central Chile and the AAO is not significant. This may in part have to do with the definition of the AAO since the index is defined around the entire zonal band and it gives more weight to hemispheric blocking events (i. e., multiple locations with blocking) rather than regional (single location) blocking in the far southeast Pacific. Blocking at just one location happens frequently, even though there is also hemispheric blocking, especially with wave 3 (Trenberth and Mo
1985). Other simple criteria, such as the "regularity" in the MJO propagation speed, seem unlikely at this point to reduce the amount of false alarms (1.5-2.5 false alarms for every correctly predicted event) and improve the diagnostic.

Even though the diagnostic is not without flaw, one may use this as an indicator of a greater likelihood of precipitation. Forecasters may employ these ideas using either the precursor MJO phase or a numerical forecast of the MJOI to gain more information. At this point, there is an increased likelihood of precipitation based on the MJO, but one most keep in mind the number of false alarms that occur.

The Elqui Valley contrasts with other regions where rain is more prevalent, normally distributed, and is clearly modulated by the phase of the MJO (e.g., Mo and Higgins 1998b; Barlow and Salstein 2006; Becker et al. 2011; Martin and Schumacher 2011). The rarity and large variability of precipitation in the Elqui Valley (only 33 strong rainfall events in 31 years of data at $\mathrm{La}$ Serena) creates challenges for using the MJOI as a longterm predictor of fall and winter rainfall.

Acknowledgments. We thank CEAZA and INIA for their support. DR is supported by FONDECYT 3110100. We are grateful for precipitation data that was provided by the Dirección General de Aguas de Chile. We also thank the three anonymous reviewers for their constructive criticism that improved the final version.

\section{REFERENCES}

Barlow, M., and D. Salstein, 2006: Summertime influence of the Madden-Julian Oscillation on daily rainfall over Mexico and Central America. Geophys. Res. Lett., 33, L21708, doi:10.1029/ 2006 GL027738.

Barrett, B. S., J. F. Carrasco, and A. P. Testino, 2012: Madden-Julian oscillation (MJO) modulation of atmospheric circulation and Chilean winter precipitation. J. Climate, 25, 1678-1688.

Becker, E. J., E. H. Berbery, and R. W. Higgins, 2011: Modulation of cold-season U.S. daily precipitation by the Madden-Julian oscillation. J. Climate, 24, 5157-5166.

Carrasco, J. F., 2006: Precipitation events in central Chile and its relation with the MJO. Proc. Eighth Int. Conf. on Southern Hemisphere Meteorology and Oceanography, Foz do Iguaçu, Brazil, INPE, 1719-1722. [Available online at http://www.dgf.uchile. cl/ACT19/COMUNICACIONES/Congresos/carrasco2.pdf.]

Carvalho, L. M. V., C. Jones, and T. Ambrizzi, 2005: Opposite phases of the Antarctic Oscillation and relationships with intraseasonal to interannual activity in the tropics during the austral summer. J. Climate, 18, 702-718.

Donald, A., H. Meinke, B. Power, A. de H. N. Maia, M. C. Wheeler, N. White, R. C. Stone, and J. Ribbe, 2006: Nearglobal impact of the Madden-Julian Oscillation on rainfall. Geophys. Res. Lett., 33, L09704, doi:10.1029/2005GL025155. 
Fu, X., B. Want, D. Waliser, and L. Tao, 2007: Impact of atmosphereocean coupling on the predictability of monsoon intraseasonal oscillations. J. Atmos. Sci., 64, 157-174.

Fuenzalida, H. A., R. Sanchez, and R. D. Garreaud, 2005: A climatology of cutoff lows in the Southern Hemisphere. J. Geophys. Res., 110, D18101, doi:10.1029/2005JD005934.

Goswami, B. N., and P. K. Xavier, 2003: Potential predictability and extended range prediction of Indian summer monsoon breaks Geophys. Res. Lett., 30, 1966, doi:10.1029/2003GL017810.

Hendon, H. H., C. Zhang, and J. D. Glick, 1999: Interannual variation of the Madden-Julian Oscillation during austral summer. J. Climate, 12, 2538-2550.

Hormazabal, S., G. Shaffer, and O. Pizarro, 2002: Tropical Pacific control of intraseasonal oscillations off Chile by way of oceanic and atmospheric pathways. Geophys. Res. Lett., 29, 1081, doi:10.1029/2001GL013481.

Jiang, X. N., D. E. Waliser, M. C. Wheeler, C. Jones, M.-I. Lee, and S. D. Schubert, 2008: Assessing the skill of an all-season statistical forecast model for the Madden-Julian oscillation. Mon. Wea. Rev., 136, 1940-1956.

Kessler, W. S., 2001: EOF representation of the Madden-Julian Oscillation and its connection with ENSO. J. Climate, 14, 3055-3061.

L'Heureux, M. L., and R. W. Higgins, 2008: Boreal winter links between the Madden-Julian oscillation and the Arctic Oscillation. J. Climate, 21, 3040-3050.

Madden, R. A., and P. R. Julian, 1994: Observations of the 40-50 day tropical oscillation: A review. Mon. Wea. Rev., 122, 814-837.

Martin, E. R., and C. Schumacher, 2011: Modulation of Caribbean precipitation by the Madden-Julian oscillation. J. Climate, 24, 813-824.

Matthews, A. F., and M. P. Meredith, 2004: Variability of Antarctic circumpolar transport and the Southern Annular Mode associated with the Madden-Julian Oscillation. Geophys. Res. Lett., 31, L24312, doi:10.1029/2004GL021666.

Mo, K. C., and R. W. Higgins, 1998a: The Pacific-South American modes and tropical convection during the Southern Hemisphere winter. Mon. Wea. Rev., 126, 1581-1596.

, and - 1998b: Tropical influences on California precipitation. J. Climate, 11, 412-430.
Montecinos, A., M. V. Kurgansky, C. Muñoz, and K. Takahashi, 2011: Non-ENSO interannual rainfall variability in central Chile during austral winter. Theor. Appl. Climatol., 1, 1-12.

Pohl, B., and A. J. Matthews, 2007: Observed changes in the lifetime and amplitude of the Madden-Julian oscillation associated with interannual ENSO sea surface temperature anomalies. J. Climate, 20, 2659-2674.

—, N. Fauchereau, C. J. C. Reason, and M. Rouault, 2010: Relationships between the Antarctic Oscillation, the MaddenJulian oscillation, and ENSO, and consequences for rainfall analysis. J. Climate, 23, 238-254.

Rutllant, J., and P. Aceituno, 1991: Southern Hemisphere circulation signals in connection with winter rainfall forecasting in central Chile. International Atomic Energy Agency and United Nations Educational Scientific and Cultural Organization, International Centre for Theoretical Physics Internal Rep. IC/91/64, 20 pp.

_ , and H. Fuenzalida, 1991: Synoptic aspects of the central Chile rainfall variability associated with the Southern Oscillation. Int. J. Climatol., 11, 63-76.

Saha, S., and Coauthors, 2010: The NCEP Climate Forecast System Reanalysis. Bull. Amer. Meteor. Soc., 91, 1015-1057.

Seo, K.-H., W. Wang, J. Gottschalck, Q. Zhang, J. K. E. Schemm, W. R. Higgins, and A. Kumar, 2009: Evaluation of MJO forecast skill from several statistical and dynamical forecast models. J. Climate, 22, 2372-2388.

Trenberth, K. E., and K. C. Mo, 1985: Blocking in the Southern Hemisphere. Mon. Wea. Rev., 113, 3-21.

Van den Dool, H. M., and S. Saha, 1990: Frequency dependence in forecast skill. Mon. Wea. Rev., 118, 128-137.

Vargas, G., J. Rutllant, and L. Ortlieb, 2006: ENSO tropicalextratropical climate teleconnections and mechanisms for Holocene debris flows along the hyperarid coast of western South America $\left(17^{\circ}-24^{\circ}\right.$ S). Earth Planet. Sci. Lett., 249, 467-483.

Waliser, D. E., K. M. Stern, and C. Jones, 2003: Potential predictability of the Madden-Julian oscillation. Bull. Amer. Meteor. Soc., 84, 33-50.

Wheeler, M. C., and H. H. Hendon, 2004: An all-season real-time multivariate MJO index: Development of an index for monitoring and prediction. Mon. Wea. Rev., 132, 1917-1932. 